\title{
A FUNDAMENTAL DIFERENÇA ENTRE O CONCEITO DE TEMPO NA CIÊNCIA HISTÓRICA E NA FÍSICA: INTERPRETAÇÃO DE UM TEXTO HEIDEGGERIANO
}

\section{THE FUNDAMENTAL DIFFERENCE BETWEEN THE CONCEPT OF TIME IN HISTORICAL SCIENCE AND IN PHYSICS: INTERPRETATION OF A HEIDEGGER'S TEXT}

RESUMO - Este artigo tem como escopo fazer uma interpretação fenomenológica do texto da aula de habilitação pronunciada por Martin Heidegger em 1915 na Universidade de Friburgo. Apesar de ser um texto muitas vezes citado pelos estudiosos da obra heideggeriana, pouco se conhece a seu respeito e, sobretudo, de que maneira algumas ideias - as quais serão desenvolvidas em Ser e tempo (1927) - já estão embrionariamente presentes nesta aula de habilitação. Neste sentido, seguindo a indicação do próprio título, pretende-se evidenciar em que sentido há uma diferença fundamental, segundo Heidegger, entre o conceito de tempo na ciência histórica e na física. Aspecto importante da presente interpretação consiste em vir acompanhada da tradução inédita de passagens significativas do texto em questão.

PALAVRAS-CHAVE - Conceito de tempo. Ciência histórica. Física. Martin Heidegger.

ABSTRACT - This article scoped a phenomenological interpretation of the text of the enabling lecture spoken by Martin Heidegger in 1915 at Freiburg's University. Despite being a text often cited by scholars of Heidegger's work, little is known about it, and especially how some ideas - which will be developed in Being and Time (1927) - are

* Doutor em filosofia pela Universidade Federal do Rio de Janeiro (UFRJ) e professorpesquisador da Pontifícia Universidade Católica de Campinas (PUC-Campinas). E-mail: $<$ renatokirchner@puc-campinas.edu.br>.

\begin{tabular}{|l|l|l|l|l|l|}
\hline Veritas & Porto Alegre & v. 57 & n. 1 & jan./abr. 2012 & p. 128-142 \\
\hline
\end{tabular}


already present, in embryo, in the enabling lecture. Then, following the signs of the title itself, we intend to show in what sense there is a fundamental difference, according to Heidegger, between the concept of time in the Historical Science and Physics. An important aspect of this interpretation is that it follows an unpublished translation of significant passages of the mentioned text.

KEYWORDS - Concept of Time. Historical Science. Physics. Martin Heidegger.

"O conceito de tempo na ciência histórica" ("Der Zeitbegriff in der Geschichtswissenschaft") é o título da aula de habilitação proferida por Heidegger no dia 27 de julho de 1915, em Friburgo ${ }^{1}$. O texto foi publicado pela primeira vez no Zeitschrift für Philosophie und philosophische Kritik, em 1916 e, posteriormente, no primeiro volume da obra completa (Gesamtausgabe), em 1972, pela editora Vittorio Klostermann, de Frankfurt.

Trata-se do primeiro escrito importante de Heidegger em que é explícita sua preocupação com a temática do tempo e, também, da história. Apesar de sua importância no conjunto da obra heideggeriana e dos muitos estudos realizados aqui no Brasil sobre o pensamento deste filósofo, poucas referências são feitas a este documento. Neste artigo, objetivamos realizar uma dupla tarefa: de um lado, traduzir passagens significativas da aula de habilitação e, de outro, comentar as ideias fundamentais que perpassam o pensamento heideggeriano pelos idos de 1915, tendo por base o texto da aula de habilitação.

Numa nota de rodapé do § 80 de Ser e tempo, obra principal publicada somente em 1927, o filósofo reconhece: "Uma primeira tentativa de se interpretar o tempo cronológico e os números na história encontra-se na aula de habilitação, dada pelo autor na Universidade de Friburgo (semestre de verão, 1915)"2. Segundo as palavras do próprio filósofo, trata-se de "uma primeira tentativa (Versuch) de interpretar o tempo cronológico (chronologischen Zeit) e os números na história (Geschichtszahl). Na mesma nota lê-se ainda: "As relações entre os números históricos, o tempo calculado astronomicamente e a temporalidade e historicidade do ser-aí (Dasein) necessitam de uma ampla investi-

1 Cf. SAFRANSKI, Rüdiger. Heidegger: um mestre da Alemanha entre o bem e o mal. São Paulo: Geração Editorial, 2000, p. 94.

2 Cf. HEIDEGGER, Martin. Ser e tempo, § 80, nota 233, p. 514; HEIDEGGER, Martin. "Der Zeitbegriff in der Geschichtswissenschaft", p. 356-375. 
gação"3. Esta nota evidencia claramente a inquietação de Heidegger cerca de dez anos antes da publicação de Ser e tempo. Seguindo estes esclarecimentos, procuraremos apontar e analisar interepretativamente algumas das ideias condutoras presentes no texto da aula de habilitação.

Como epígrafe ao texto da aula, Heidegger cita um pensamento de Mestre Eckhart: "Tempo é o que se altera e diversifica, a eternidade se mantém simples" ("Zeit ist das, was sich wandelt und mannigfaltigt, Ewigkeit hält sich einfach") ${ }^{4}$. Chama atenção que Heidegger não tenha grifado a palavra "einfach", que significa "simples". Literalmente, "einfach" diz "sem dobra", "sim-ples" (sine plex). De fato, ele grifou "wandelt" e "mannigfaltigt". Neste caso, o tempo é o que se trans-forma e se multiplica. A ênfase nestas palavras revela duas ideias importantes: 1) que o tempo muda, se altera, implicando, portanto, uma passagem entre o antes e o depois; 2) que o tempo é múltiplo, que possui várias dimensões.

Poderíamos entrar aqui em várias considerações e aprofundálas. No entanto, cabe prestar atenção, de passagem, apenas para o seguinte: de certo modo, na primeira ideia está presente a concepção aristotélica de tempo e, nesse caso, devemos considerar que também Mestre Eckhart movimenta-se dentro desta concepção, concepção aliás predominante em todo o pensamento ocidental; na segunda ideia, quanto à multiplicidade do tempo e que o tempo certamente não é unidimensional, podemos perceber que, do mesmo modo como o "ser" deve ter

3 Chama atenção o fato de Heidegger mencionar vários textos relativos à cronologia ou cronometria. Ele cita G. Simmel, Das Problem der historischen Zeit, de 1916; segundo Heidegger, as duas obras fundamentais sobre a formação da cronologia histórica são: Josephus Justus Scaliger, De emendatione temporum, de 1583, e Dionysius Petavius, Opus de doctrina temporum, de 1627; sobre a antiga medição do tempo, G. Bilfinger, Die antiken Stundenangaben, de 1888; Der bürgerliche Tag. Untersuchungen über den Beginn des Kalendertages im klassischen Altertum und im christlichen Mittelalter, de 1888; H. Diels, Antike Technik, de 1920; Friedrich Rühl trata sobre a cronologia recente em Chronologie des Mittelalters und der Neuzeit, de 1897. O mesmo texto de G. Bilfinger é também citado por Heidegger no volume 64 das obras completas (cf. HEIDEGGER, Martin. Der Begriff der Zeit. 1. Der Begriff der Zeit (1924); 2. Der Begriff der Zeit (Vortrag 1924), nota 4, p. 68).

4 Cf. HEIDEGGER, Martin. "Der Zeitbegriff in der Geschichtswissenschaft", p. 357. Embora Heidegger não esclareça, a epígrafe provém do sermão 44 dos assim chamados sermões alemães eckhartianos. Na tradução brasileira, cf. ECKHART, Mestre. Sermões alemães. Bragança Paulista: Edusf; Petrópolis: Vozes, 2006, p. 252-256. Estudos importantes a respeito desta aula de habilitação são os de REGEHLY, Thomas. "Historische und erfüllte Zeit. Walter Benjamins Kritik an Heideggers Antrittsvorlesung über den 'Zeitbegriff in der Geschichtswissenschaft' (1916)". In: Die Zeit Heideggers, Frankfurt am Main: Peter Lang, 2002, p. 141-152; IRLENBORN, Bernd. "Zeitlichkeit und Zeitrechnung beim frühen Heidegger". In: Die Zeit Heideggers, Frankfurt am Main, Peter Lang, 2002, p. 161-172; CAPELLE, Philippe. "Heidegger et maître Eckhart". In: Revue des Sciences Religieuses, ano 70, n. 1, jan. 1996, p. 113-124. 
mais de um "significado", também o "tempo" é "multifário", ou seja, o "tempo" deve ter mais de uma dimensão. Esta segunda ideia remete diretamente ao título Das múltiplas significações do ser em Aristóteles, de Franz Brentano, publicado em 1862, livro do qual Heidegger, ao lado das Investigações lógicas, de Edmund Husserl, buscava uma compreensão para a "questão do ser" já no verão de 1907, quando ainda cursava o ginásio ${ }^{5}$. Fazer essas considerações a respeito da epígrafe é importante, pois ela evidencia a dimensão em que Heidegger se movimenta no texto da aula de habilitação, ou seja, de algum modo, ela condensa as ideias condutoras presentes no próprio texto. É o que procuraremos demonstrar a seguir.

O próprio título do texto denuncia que Heidegger ocupa-se com o conceito de tempo enquanto problema relacionado à história, ou melhor, à ciência histórica. A partir disso, é possível fazer uma interpretação do texto em dois momentos distintos: de um lado, a preocupação de Heidegger consiste em estabelecer uma diferença básica entre o modo de conceber o tempo nas ciências naturais e o modo de conceber o tempo nas ciências históricas, procurando encontrar os "limites" de uma em relação à outra; de outro lado, preocupa-se ele em mostrar que o conceito de tempo na ciência histórica possui um significado todo peculiar. Por isso afirma, ao final do texto, que todo e qualquer número histórico só possui sentido (Sinn) e valor (Wert) no âmbito da ciência histórica, na medida em que se levar em consideração o significado do conteúdo histórico (inhaltlich historisch Bedeutsame).

$\mathrm{Na}$ primeira parte do texto, fazendo uso de uma terminologia e temática próprias do neokantismo, o autor aborda problemas que ultrapassam e, por isso mesmo, já não podem mais ser resolvidos nas

5 Dois textos exerceram sobre o jovem Heidegger uma influência decisiva: a dissertação de Franz Brentano, Das múltiplas significações do ser em Aristóteles, de 1862, e as Investigações lógicas, de Husserl, obra publicada pela primeira vez em 1900-1901. Em Meu caminho para a fenomenologia, Heidegger diz: "Das Investigações lógicas de Husserl esperava um estímulo decisivo com relação às questões suscitadas pela dissertação de Brentano"; e no diálogo De uma conversa da linguagem entre um japonês e um pensador: "[...] nos últimos anos do ginásio, no verão de 1907, a questão do ser me encontrou na forma da dissertação de Franz Brentano, professor de Husserl". Cf. a respeito HEIDEGGER, Martin. "Aus einem Gespräch von der Sprache zwischen einem Japaner und einem Fragenden". In: Unterwegs zur Sprache. Stuttgart: Günther Neske, 1997, principalmente p. 92-92; "Meu caminho para a fenomenologia". In: Conferências e escritos filosóficos. São Paulo: Abril Cultural, 1973, p. 493-500; também Ser e tempo. Bragança Paulista: Edusf; Petrópolis: Vozes, 2006, § 8, p. 69-70). Cf. ainda os estudos de BERNET, Rudolf. "Origine du temps et temps originaire chez Husserl et Heidegger". In: Revue Philosophique de Louvain, vol. 85, n. 68, nov. 1987, p. 499-521; IANNIELLO, Epifània. "La conscienza del tempo come flusso intenzionale in Husserl". In: Sapienza, vol. 50, fasc. 4, out./dez. 1997, p. 467-484. 
estritas fronteiras kantianas de uma teoria do conhecimento. Assim, embora se trate "ainda" de uma investigação epistemológica, procura estabelecer a especificidade do conceito de tempo da ciência histórica em oposição ao conceito das ciências físicas.

Num primeiro momento, a ênfase recai na análise do que Heidegger chama de "estrutura lógica do conceito de tempo". Deve-se determinar, então, "a estrutura do conceito de tempo". "Podemos reconhecer a estrutura do conceito de tempo da história a partir de sua fundamentação na ciência histórica", reconhece Heidegger. A pergunta que ele se coloca é: "Que estrutura (Struktur) deve ter o conceito de tempo na ciência histórica para poder desempenhar a função (Ziel) como conceito de tempo de acordo com a finalidade (Funktion) desta ciência?"6 Está em jogo dar visibilidade ao conceito de "tempo histórico" (historischen Zeit) a partir do conceito de "tempo em geral" (Zeit überhaupt). O termo "geral" possui um sentido eminentemente ontológico. Entretanto, toda e qualquer determinação ôntica nasce necessariamente de uma determinação ontológica fundamental. Ora, a ciência histórica é uma ciência ôntica. Contudo, essa diferenciação se tornará mais evidente na medida em que Heidegger demonstra que o conceito de tempo histórico tem um significado todo peculiar, se comparado com o conceito de tempo das ciências físicas. Por isso escreve:

A filosofia da natureza antiga e medieval procurava investigar a essência metafísica dos fenômenos inerentes à realidade imediata e suas causas ocultas. Em oposição a esta especulação metafísica sobre a natureza, a ciência de Galileu significa metodicamente algo completamente novo. Esta pretende exercer o domínio sobre a diversificação dos fenômenos através da lei e seu resultado novo e particular consiste como chega à lei.

Tendo presente o pensamento de Eckhart sobre o tempo, na qual ainda repercute de algum modo o conceito de tempo aristotélico ${ }^{8}$, Heidegger está mesmo interessado na compreensão que está "em oposição", isto é, no modo como o tempo passa a ser compreendido no início da modernidade. A diferença fundamental reside no modo "completamente novo" como a geração de Galileu aprendeu o tempo "metodologicamente". Segundo Heidegger, no novo método reside uma dupla particularidade: a) afirma-se uma suposição ou hipótese, que possibilita compreender os fenômenos de um âmbito determinado a partir de uma lei geral, no caso,

HEIDEGGER, Martin. "Der Zeitbegriff in der Geschichtswissenschaft”, p. 359.

HEIDEGGER, Martin. "Der Zeitbegriff in der Geschichtswissenschaft", p. 361.

8 Cf. Aristóteles, Física, livro IV, 119 a 9s. 
os fenômenos relacionados ao movimento; b) a suposição ou hipótese não afirma, de modo algum, uma qualidade oculta (vergorgene Qualität) como causa explicativa dos fenômenos, mas contém relações matematicamente compreensíveis, ou melhor, mensuráveis, entre os momentos do fenômeno concebidos idealmente.

Formulado desse modo, vê-se que Galileu levou a efeito, pela primeira vez, um método científico que alcançou predomínio e legitimidade do decorrer dos últimos séculos, de modo a fazer-se presente e operante nas mais diversas ciências, especialmente nas ciências físico-naturais. É possível concluir, então, que aqui se define a finalidade da física como ciência, quer dizer, de reduzir todos os fenômenos do mundo físico a um conceito de unidade, a saber, a leis fundamentais matematicamente fixáveis a partir de uma "dinâmica geral" (allgemeinen Dynamik). Dessa metodologia resulta, consequentemente, que, sempre que e quando o tempo é medido, determina-se uma quantidade (Soviel). A indicação de quantidade reúne numa unidade os pontos de tempo nela transcorridos e, assim, acaba-se fazendo um corte na escala temporal (Zeitskala), destruindo com isso o "tempo verdadeiro" (eigentliche Zeit) em seu fluir e, desse modo, qualquer "unidade de tempo" é forçosamente hipostasiado, enfim, "sedimentado". O fluxo (Fluß) é detido, congela-se, torna-se superfície e, somente como superfície, é passível de mensuração. Dessa maneira, o tempo transforma-se numa "ordenação homogênea" (homogenen Stellenordnung), transforma-se em escala, em parâmetro $(\text { Parameter })^{9}$. Por isso, na sequência do texto da aula de habilitação podemos ler:

Contudo, na maioria das vezes, isso não é visto: na teoria da relatividade, na medida em que é uma teoria física, está em jogo o problema da mensuração do tempo, porém, não o tempo em si mesmo. Na teoria da relatividade o conceito de tempo permanece intocado; nela apenas se confirma uma medida elevada, a qual foi apresentada anteriormente como o conceito de tempo característico das ciências naturais, a saber, como o caráter determinável de homogêneo e quantitativo. O caráter matemático do conceito de tempo físico não pode ser expresso de uma maneira mais precisa através disso, na medida em que ele pode ser apresentado ao lado do espaço tridimensional enquanto quarta dimensão e, ao lado dele, através da dimensão não-euclidiana, isto é, que ele é elaborado mais como uma geometria tridimensional.

Se nós quisermos unicamente passar por cima disso, isto é, se nós quisermos representar a estrutura do conceito de tempo na ciência histórica, então parece ser questionável, antes de mais nada, se aqui

Sobre os conceitos "tempo e espaço" e, também, sobre "Aritóteles e Newton", cf. HEIDEGGER, Martin. Que é uma coisa?, §§ 5 e 18, respectivamente p. 25-33 e 86-93. 
ainda se deixa colocar um novo problema (ein neues Problem stellen läßt). Pois, também para a ciência histórica, o tempo é igualmente um modo de ordenação à medida que os acontecimentos resguardam seu lugar de tempo determinado e são fixados a partir disso como sendo históricos ${ }^{10}$.

Para Heidegger, mesmo na teoria da relatividade de Einstein, uma das conhecidas teorias físicas do tempo, está em jogo o problema da "mensuração do tempo" (Zeitmessung) e "não o tempo em si mesmo" (nicht um die Zeit an sich). Com efeito, mesmo na teoria da relatividade, o conceito de tempo permanece inalterado e intocado ${ }^{11}$, ou seja, de Galileu a Einstein a concepção do tempo na física não se modificou, sendo sua função básica tornar possível a mensurabilidade do tempo. O tempo constitui-se, então, num momento essencial e necessário na definição do movimento, que é um dos principais objetos da física. Ora, para possibilitar a medida, o tempo deve tornar-se mensurável, o que é possível somente, se for "pensado" (tomado) como um fluxo uniforme, isto é, se for identificado com o próprio espaço ${ }^{12}$.

Salvaguardados o limite e propósito de Heidegger, está em jogo, em primeiro plano, traçar uma diferença entre o conceito de tempo da física ("homogeneidade quantitiva") e o conceito de tempo da ciência histórica ("heterogeneidade qualitativa"). Vejamos isso melhor a partir de outra passagem da aula de habilitação:

Encontramo-nos aqui diante de uma alternativa: a partir do conceito anteriormente mencionado, ou não possuímos nenhum conceito histórico, na medida em que não se mostra, porque a nua determinação de tempo deve poder constituir-se num conceito universal a partir de um conceito histórico e o qual também é determinado temporalmente pela física a partir de movimentos precedentes, - ou então: temos diante de nós um conceito histórico que de fato lhe corresponde. Desse modo, portanto, a determinação de tempo nela encontrada é totalmente peculiar e própria, e esta só pode ser compreendida a partir da essência da ciência histórica.

Ao menos isto parece ter-se evidenciado para nós: há um problema no conceito de tempo da ciência histórica (es steckt ein Problem im Zeitbegriff der Geschichtswissenschat). Pois ele tem sentido e direito se nós perguntarmos pela estrutura do conceito de tempo histórico. Nós só poderemos lê-la em sua função na ciência histórica, função esta que, por sua vez, apenas é compreensível a partir do objetivo e do objeto da ciência histórica ${ }^{13}$.

10 HEIDEGGER, Martin. "Der Zeitbegriff in der Geschichtswissenschaft", p. 366-367.

11 HEIDEGGER, Martin. "Der Zeitbegriff in der Geschichtswissenschaft", p. 366.

12 Cf. DASTUR, Françoise. Heidegger e a questão do tempo. Lisboa: Instituto Piaget, 1997, p. 26.

${ }^{13}$ HEIDEGGER, Martin. "Der Zeitbegriff in der Geschichtswissenschaft", p. 367. 
Heidegger chega à evidência de que o conceito de tempo da ciência histórica deve ser "totalmente peculiar e próprio". A partir disso, acaba tendo diante dos olhos um fenômeno novo, que é, na verdade, o problema central da aula de habilitação. É necessário ver e entender o "sentido" de uma possível "estrutura do conceito de tempo histórico", a qual só pode estar relacionada diretamente com a própria história, ou melhor, com o objeto que esta se propõe investigar, na medida em que se justificar ontologicamente tal direito. Em certo sentido, pode-se admitir, Heidegger chega a tomar uma posição crítica - naturalmente implícita - em relação ao modo como os historiadores realizam suas investigações em história ${ }^{14}$. Assim, é necessário ver e entender por que, segundo Heidegger, no conceito de tempo da ciência histórica reside um problema (es steckt ein Problem im Zeitbegriff der Geschichtswissenschat) ${ }^{15}$. Está em jogo aqui, compreender fundamentalmente o que o pensador vê como "estrutura (Struktur) do conceito de tempo histórico" e que "função" (Funktion) desempenha.

Com efeito, se as ciências naturais operam com os números como meras quantidades, as ciências históricas, ao contrário, não devem tratar tais dados com a mesma objetividade. Desse modo, a ciência histórica, para ser rigorosa ao modo de descrever os fenômenos de seu campo de investigação, necessita compreender os dados históricos de um modo que não seja quantitativo, mas qualitativo, que não seja homogêneo, mas heterogêneo. Portanto, a ciência histórica não pode descrever os fenômenos de seu campo de investigação emprestando critérios de outra

14 No âmbito das investigações heideggerianas deveríamos perguntar e aprofundar vários outros aspectos. Nesse sentido, deveríamos perguntar: de quais fontes parte ou se inspira Heidegger para chegar a uma diferenciação conceitual entre "historicidade" e "história", por exemplo? São muitas. Na aula de habilitação de 1915 são citados J. Bodinus, E. Meyer, E. Bernheim, J. G. Droysen, E. Troeltsch, H. Rickert, L. Ranke, sendo que os dois últimos, ao lado de Windelband, G. Simmel e G. Misch, são mencionados também no $\$ 77$ de Ser e tempo. Entretanto, no capítulo "temporalidade e historicidade", dois outros autores são realmente fonte de inspiração importantíssima para Heidegger: Wilhelm Dilthey e Paul Yorck von Wartenburg, o Conde Yorck. Ele mesmo atesta isso no início do § 77: "A discussão empreendida acerca do problema da história nasceu da assimilação do trabalho de Dilthey. Foi confirmada e consolidada pelas teses do Conde Yorck, dispersas em sua correspondência com Dilthey" (HEIDEGGER, Martin. Ser e tempo, § 77, p. 490-491). Além destes autores, também Jacob Burckhardt é significativo. No livro em que Heidegger interpreta Parmênides, reconhece: "Tudo que é historiográfico (Historische) orienta-se a partir do histórico (Geschichtliche). A história, ao contrário, não tem nenhuma necessidade da historiografia. O homem da historiografia é, sempre, apenas um técnico, um jornalista. Um pensador da história é totalmente distinto do historiógrafo. Jacob Burckhardt não é nenhum historiador, mas um verdadeiro pensador da história (Geschichtsdenker)" (HEIDEGGER, Martin. Parmenides. Frankfurt am Main: Vittorio Klostermann, 1992, p. 94-95).

15 HEIDEGGER, Martin. "Der Zeitbegriff in der Geschichtswissenschaft", p. 367. 
ciência, ficando pressuposto que deve possuir ou elaborar seus próprios critérios e métodos investigativos. Daí as palavras de Heidegger:

O objeto histórico, enquanto histórico, é sempre passado; tomado rigorosamente, ele não existe mais. Entre ele e o historiador há uma distância temporal (Zeitferne). O passado (Vergangenheit) sempre tem sentido somente, na medida em que é visto a partir de um presente (Gegenwart). O passado não apenas não é mais, considerado a partir de nós, ele era também um outro (Anderes) como nós e nossas relações de vida hoje são no presente. O tempo possui - tanto assim já se vê aqui - um significado totalmente original no âmbito da história (Die Zeit hat in der Geschichte eine ganz originale Bedeutung). Somente onde esta alteridade (Andersheit) qualitativa do tempo passado se impõe a um presente consciente, está-se desperto para o sentido do ser histórico. $\mathrm{Na}$ medida em que o passado histórico sempre é uma alteridade de objetivação de vida humana (Menschlebens) e nós mesmos vivemos e agimos nele, é porque nos é dada antecipadamente a possibilidade (vornherein die Möglichkeit gegeben) de compreender o passado, de modo que ele não pode ser comparado com nenhum outro. Contudo, o abismo temporal entre o historiador e seu objeto continua existindo. Se ele quiser descrever o abismo temporal, então ele deve ter, de um modo ou de outro, este objeto diante de si. Trata-se de superar o tempo sim, mas acostumando-se a ver como se constitui o abismo temporal do presente em relação ao passado. A exigência de superação do tempo e, por outro lado, a descrição de algo passado como meta e objeto da ciência histórica necessariamente dado em conjunto, deve ser possível somente desde que o tempo desempenhe ali uma função ${ }^{16}$.

Um dos questionamentos centrais aqui, em relação ao conceito de tempo na ciência histórica, parece ser: como pode o historiador alcançar seu objeto, visto que este se encontra no passado? Como vencer a distância temporal (Zeitferne)? A resposta é surpreendentemente "simples": "O passado sempre tem sentido somente, na medida em que é visto a partir de um presente. O passado não apenas não é mais, considerado a partir de nós, ele era também um outro como nós e nossas relações de vida hoje são no presente". Heidegger não quer dizer apenas que não é possível interpretar algum fato passado sem considerar o presente, mas toda e qualquer interpretação do passado radica sempre já num presente bem determinado. Melhor, todo presente já é, em certo sentido, também passado, na medida em que, todo e qualquer agora, quando o pronunciamos e reconhecemos de algum modo, já não é mais presente, mas passado. A rigor, o passado possui a mesma vitalidade do presente, isto é, desde que seja visto corretamente a partir do presente. O passado, para o historiador, deve estar vitalmente presente em seu presente. É nisso que reside o "significado totalmente original no âmbito

${ }^{16}$ HEIDEGGER, Martin. "Der Zeitbegriff in der Geschichtswissenschaft", p. 369-370. 
da história" (Die Zeit hat in der Geschichte eine ganz originale Bedeutung), reconhece Heidegger.

Para aprofundar e esclarecer isso melhor, convém acompanhar e compreender a passagem seguinte:

O conceito de tempo na ciência histórica não possui nada do caráter homogêneo do conceito do tempo natural. O tempo histórico também não pode, por isso mesmo, ser expresso matematicamente através de uma fila como se houvesse aí uma lei que determinasse os tempos um após o outro. Os momentos do tempo físico se diferenciam apenas através da colocação numa fila. Os tempos históricos seguem-se também um após o outro - senão eles não seriam naturalmente tempo -, porém, cada qual é, em sua estrutura conteudística, um outro. $O$ qualitativo do conceito de tempo histórico não significa outra coisa do que compactação (Verdichtung) - cristalização (Kristallisation) - de uma objetivação de vida dada dentro da história. Portanto, a ciência histórica não trabalha com quantidades. Todavia, o que são os números da história então? Com o conceito "a fome em Fulda no ano de 750", o historiador não pode começar com o número 750; não pode interessar-lhe o número como quantum, como um elemento em que a fileira numérica de 1 até o infinito tem seu lugar determinado, sendo possível dividi-lo, por exemplo, por 50 e assim por diante. O número 750 , e todo e qualquer outro número histórico, só possui sentido (Sinn) e valor (Wert) no âmbito da ciência histórica, na medida em que se levar em consideração o significado do conteúdo histórico (inhaltlich historisch Bedeutsame). Trecento e Quattrocento não são mais que conceitos quantitativos. Na física e na história, a pergunta pelo quando (Wann) possui um sentido totalmente diverso ${ }^{17}$.

Podemos destacar duas ideias importantes nesta passagem do texto da aula de habilitação: a) embora de uma forma não explícita, vemos nesse texto a ideia norteadora segundo a qual o tempo na ciência histórica diferencia-se essencialmente do tempo como fila de agoras, sem começo e sem fim, isto é, como se a todo agora seguisse pura e simplesmente um novo agora e, assim, indefinidamente. Decorre dali que o conceito de tempo na ciência histórica não possui o caráter homogêneo do conceito do tempo natural. Por isso mesmo, o tempo histórico também não pode ser expresso matematicamente através de uma fila como se houvesse uma lei que determinasse os "agoras" um após o outro. Nessa ideia manifesta-se, de algum modo, o conceito vulgar de tempo, quer dizer, que o tempo é uma pura sequência de agoras, sem começo e sem fim. E assim, pensa Heidegger, na ciência histórica, "a pergunta pelo quando (Wann) possui um sentido totalmente diverso". Diante disso, podemos precisar melhor o problema com o qual Heidegger se depara: b) de um lado, se o tempo não deve ser visto unicamente como uma mera

${ }_{17}$ HEIDEGGER, Martin. "Der Zeitbegriff in der Geschichtswissenschaft", p. 373. 
sequência ou fila de agoras, sem começo e sem fim, quer dizer, de modo indeterminado (o que equivale ao quantitativo nas ciências naturais), de outro lado, coloca-se uma nova questão: qual o sentido do "agora enquanto data histórica", por exemplo? Qual a estrutura significativa de todo e qualquer "agora" enquanto "data histórica" ? ${ }^{18}$ De fato, todo e qualquer conteúdo histórico possui "significado" (inhaltlich historisch Bedeutsame), ou seja, tem "sentido" (Sinn) e "valor" (Wert).

Heidegger pergunta-se nestes termos: "O que são os números da história, então?", ou seja, qual o caráter do propriamente qualitativo em termos históricos? A partir disso, o filósofo determina propriamente como concebe o qualitativo na ciência histórica e o diz de uma maneira lapidar: "O qualitativo do conceito de tempo histórico não significa outra coisa do que compactação (Verdichtung) - cristalização (Kristallisation) - de uma objetivação de vida dada dentro da história. Portanto, a ciência histórica não trabalha com quantidades". Embora de modo não explícito, pode-se ler aqui: o conceito de tempo histórico implica, de algum modo, compreender que a própria vida humana se temporaliza, se historializa. O ser humano pode "voltar" ao passado, porque a vida se compacta, se cristaliza sob formas significativas, de sentido e valor.

Assim, por exemplo, se analisarmos sob os olhos da fenomenologia, não somente e necessariamente datas importantes como da proclamação da independência, da proclamação da república ou da abolição da escravatura no Brasil, publicamente reconhecidas e comemoradas, constituem-se compactações ou cristalizações de vida e história humanas. De uma maneira muito mais próxima e imediata, porém, a data de nosso nascimento não é, a rigor, uma mera data, muito menos mero número. Evidencia-se isso no fato de, em geral, não pensarmos necessariamente "no dia do nascimento" como algo perdido num passado mais próximo ou mais distante. Porquanto, toda vez que, na passagem de outro ano de vida, o que co-memoramos? Dizemos manifestamente: "Nossa vida, nossa existência!" Na verdade, porém, tornamos memorável "cada passagem do tempo em nossa vida" e é justamente isso que dá sentido à constituição do "co" da co-memoração. Nesse sentido, dizemos também às vezes: "re-cordamos", isto é, reunimos e trazemos para junto do "coração", tudo que já fomos e somos, mas também alimentamos a esperança de poder-ser o ainda-não-sido em cada nova passagem do tempo em nossa vida. De fato, cada passagem de ano, cada dia que passa, cada hora, cada segundo, cada milionésimo de segundo constituem o (co)memorável de nossa vida, de nossa existência.

18 Nesta perspectiva, seria oportuno um estudo mais detido e aprofundado de $A$ doutrina das categorias e significados de Duns Escoto (HEIDEGGER, Martin. Die Kategorien- und Bedeutungslehre des Duns Scotus. Tübingen: J.C. Mohr, 1916). 
Desse modo, à procura de determinar o conceito de tempo da física, Heidegger evidencia que o tempo nela compreendido caracteriza-se como tempo homogêneo (homogen) e quantitativo (quantitativ). Assim, sem prejuízo algum para a própria física enquanto ciência, é possível perguntar: se o tempo medido ("compreendido") pela física é sempre homogêneo e quantitativo, o que é dito através de expressões como "ordenação homogênea" (homogenen Stellenordnung), como tematizar o tempo que está nela previsto e pressuposto, ou seja, que tempo é este que se revela em expressões como "tempo verdadeiro" (eigentliche Zeit), "tempo em geral" (Zeit überhaupt), "dinâmica geral" (allgemeinen Dynamik) e "o tempo em si mesmo" (um die Zeit an sich)? A partir desses questionamentos, qual seria propriamente o conceito de tempo da ciência histórica?

A princípio, parece evidente que a ciência histórica não trabalha nem opera com quantidades e, portanto, é óbvio que se opõe ao conceito do tempo da física. A questão central, porém, consiste exatamente em mostrar e demonstrar isso. Num primeiro momento, é importante ter presente que, quando a ciência histórica se ocupa com determinada datação, por exemplo, ela não se ocupa com mera data. É que, a toda e qualquer data histórica, sempre se atribui alguma significação, algum sentido, algum valor. Por isso mesmo, não pode ser reduzida ao modelo, ou melhor, ao parâmetro epistemológico das ciências da natureza e, em particular, à física. Em questão está, portanto, um modo de tematizar o "tempo em si mesmo", "o tempo verdadeiro", tratando-se então de uma questão de ordem ontológica.

Embora o conceito de tempo ainda não seja abordado no texto da aula de habilitação como em diversos textos heideggerianos posteriores, é notória aqui a preocupação - Heidegger conta, então, com 25 anos de idade - com o "tempo em si mesmo". De fato, esta expressão possui um sentido eminentemente ontológico!

A partir do que vimos até aqui, é possível perceber que já estão presentes no texto da aula de habilitação, embora ainda não explícitos e muito menos minuciosamente elaborados, conceitos importantes como significância (Bedeutsamkeit), possibilidade de datação (Datierbarkeit), lapso de tempo (Gespanntheit) e tempo público (Öffentlichkeit), conceitos que Heidegger elaborará em vários textos importantes da década de 1920. Não é mera casualidade, portanto, que Heidegger cite o texto da aula de habilitação numa nota de rodapé do § 80 de Ser e tempo. Uma evidência do que afirmamos reside em frases e expressões como "distância temporal" (Zeitferne), "separação temporal" (zeitliche Kluft), "significado do conteúdo histórico" (inhaltlich historisch Bedeutsame), "o tempo possui um significado totalmente original no âmbito da história" (Die Zeit hat in der Geschichte eine ganz originale Bedeutung), entre outras empregadas pelo filósofo na aula de habilitação. 
De fato, nos textos contemporâneos a Ser e tempo, a preocupação de Heidegger é determinar fenomenologicamente a constituição plena do "quando" ("agora") do tempo sob a forma de uma análise rigorosa do tempo ocupado (besorgte Zeit), do tempo do mundo (Weltzeit) e da intratemporalidade (Innerzeitlichkeit) ${ }^{19}$. Em vários textos heideggerianos porteiores há passagens que apontam para as análises realizadas na aula de habilitação de 1915. É possível ver isso, por exemplo, nos §§ 78 e 80, dos quais citamos aqui duas passagens significativas:

Todavia, mais elementar do que a constatação de que o "fator tempo" (Zeitfaktor) vem à tona nas ciências da história e da natureza é que, bem antes de qualquer pesquisa temática, o ser-aí já "conta com o tempo" (mit der Zeit rechnet) e por ele se orienta (nach ihr richtet). Aqui, novamente, permanece decisivo o "contar" "com o seu tempo", inerente ao ser-aí, que antecede todo uso de instrumentos de medição, adequados à determinação temporal. Este contar antecede o uso, possibilitando a utilização de relógios ${ }^{20}$.

19 Heidegger ocupa-se destes temas no último capítulo de Ser e tempo e na segunda parte do livro Os problemas fundamentais da fenomenologia, que consiste num conjunto de preleções proferidas pelo filósofo na Universidade de Marburgo no semestre de verão de 1927, ou seja, o ano em que Ser e tempo foi publicado no Jahrbuch für Philosophie und phänomenologische Forschung por Edmund Husserl. De fato, estas duas obras são imprescindíveis para entender o contexto e, a partir disso, acompanhar devidamente a elaboração heideggeriana do conceito de tempo. Nesse intuito, é necessário aprender a distriguir modos e níveis ônticos e ontológicos em que Heidegger se movimenta em suas análises do "fenômeno do tempo". Assim, uma quantidade significativa de conceitos entra em cena nas análises realizadas pelo pensador. Palavras como "agora" ("jetzt"), "antes" ("zuvor"), "contado" ("Gezählte"), "então" ("dann"), "futuro" ("Zukunft"), "outrora" ("damals"), "passado" ("Vergangenheit"), "presente" ("Gegenwart"), agora (Jetzt), "agora-agora" ("jetzt-jetzt"), agora-ainda-não (Noch-nicht-jetzt), agora-não-mais (Nicht-mehr-jetzt), aguardar (Gewärtigen), a pouco, ainda-não (Soeben-noch-nicht), atualidade (Gegenwart), atualizar (Gegenwärtigen), conceito de tempo (Zeitbegriff), contagem do tempo (Zeitrechnung), contar com o tempo (Rechnen mit der Zeit), ekstases (Ekstasen), fluxo contínuo de agoras (kontinuierlichen Jetzt-Flusses), fluxo temporal (Zeitfluß), impropriedade (Uneigentlichkeit), intratemporalidade (Innerzeitlichkeit), lapso de tempo (Gespanntheit), logo não mais (Sofort-nicht-mehr), porvir (Zukunft), possibilidade de datação (Datierbarkeit), propriedade (Eigentlichkeit), representação vulgar do tempo (vulgäre Zeitvorstellung), reter (Behalten), sempre já (immer schon), sequência de agoras (Abfolge der Jetzt, Folge der Jetzt ou jetzt-Ablauf), significância (Bedeutsamkeit), tempo (Zeit), tempo ocupado (besorgte Zeit), tempo do mundo (Weltzeit), tempo público ou fazer-se público do tempo (Öffentlichkeit), tempo-agora (Jetzt-Zeit), temporal (zeitlich), temporalidade (Zeitlichkeit), temporalização (Zeitigung), vigor de ter sido (Gewesenheit), dentre outras, perfazem um conceituário bastante amplo no qual Heidegger se movimenta na elaboração de seu conceito de tempo como temporalidade originária do ser-aí (Dasein).

20 HEIDEGGER, Martin. Ser e tempo, § 78, p. 498. Na mesma obra, § 69, Heidegger afirma que o projeto matemático da natureza "descobre, antecipadamente, um ser simplesmente dado que é constante (matéria), e abre o horizonte para uma perspectiva orientadora, relativa a seus momentos constitutivos e passíveis de determinação quantitativa (movimento, força, lugar e tempo)" (p. 451). 
A fim de assegurar uma possível compreensibilidade para a comprovação da origem do tempo público a partir da temporalidade fática, foi preciso caracterizar, primeiramente, o tempo interpretado na temporalidade das ocupações. E isso já para esclarecer que a essência da ocupação do tempo não reside na aplicação de determinações quantitativas de datas (zahlenmäßigen Bestimmungen bei der Datierung). Do ponto de vista ontológico-existencial, portanto, o decisivo na contagem do tempo (Zeitrechnung) não está na sua quantificação (nicht in der Quantifizierung der Zeit), mas deve ser concebido, ainda mais originariamente, a partir da temporalidade do ser-aí que conta com o tempo (sondern muß ursprünglicher aus der Zeitlichkeit des mit der Zeit rechnenden Daseins begriffen werden) $)^{21}$.

Concluindo esta análise interpretativa da aula de habilitação, poderíamos dizer que a possibilidade da ciência histórica é vista e tematizada por Heidegger, mas não ainda em sua gênese ontológica como temporalidade do ser-aí. Ele irá elaborar estes conceitos em textos de anos posteriores. Segundo ele, a condição de possibilidade do conceito de tempo da ciência histórica reside no fato de o historiador poder escolher no passado os momentos mais significativos e "recontar" ou "reconstruir" a história a partir deles, uma vez que o próprio tempo é constituído por momentos significativos, os quais projetam sempre de novo uma nova luz tanto ao passado, bem como ao futuro, mas sempre a partir do presente.

Assim, obedecendo aos limites da presente reflexão, ou seja, partindo da aula de habilitação de 1915, é possível lançar um novo olhar sobre passagens significativamente importantes de Ser e tempo como estas:

[...] "o ser-aí é histórico" não significa apenas o fato ôntico de que o homem representa um "átomo" mais ou menos importante no fluxo da história do mundo, sendo a bola deste jogo de circunstâncias e acontecimentos. A tese coloca o seguinte problema: Em que medida e em quais condições ontológicas, a historicidade, enquanto constituição essencial, pertence à subjetividade do sujeito "histórico"?22

Por isso é que, radicada na hermenêutica do ser-aí, a metodologia das ciências históricas do espírito (historischen Geisteswissenschaften) só pode receber a denominação de hermenêutica em sentido derivado ${ }^{23}$.

Com efeito, o filósofo de Messkirch reconhece no início do § 77 de Ser e tempo: "A discussão empreendida acerca do problema da história nasceu da assimilação do trabalho de Dilthey. Foi confirmada e consolidada pelas teses do Conde Yorck, dispersas em sua correspondência com Dilthey"24.

${ }^{21}$ HEIDEGGER, Martin. Ser e tempo, § 80, p. 507.

22 HEIDEGGER, Martin. Ser e tempo, § 73, p. 474.

23. HEIDEGGER, Martin. Ser e tempo, § 3, p. 78.

${ }^{24}$ HEIDEGGER, Martin. Ser e tempo, § 77, p. 490-491. 
Heidegger teve acesso a esta correspondência, que durou de 1877 a 1897, publicada na Alemanha em $1923^{25}$. Ele mostra, a partir das cartas, que havia um interesse comum, entre os dois pensadores da história, de "compreender a historicidade". De fato, o texto "A colocação da questão de Dilthey e a tendência fundamental de Yorck", do ano de 1924 e publicado no volume 64 da obra completa heideggeriana, corresponde, em forma e conteúdo, às idéias centrais desenvolvidas por Heidegger no capítulo dedicado ao tema da historicidade em Ser e tempo ${ }^{26}$. Gadamer, por exemplo, comprova exaustivamente como as idéias de Dilthey e York são fundamentais na elaboração heideggeriana da fenomenologia hermenêutica, da estrutura prévia da compreensão e da historicidade da compreensão como princípio hermenêutico ${ }^{27}$.

\section{Referências}

HEIDEGGER, M. "Der Zeitbegriff in der Geschichtswissenschaft". In: Frühe Schriften. Frankfurt am Main: Vittorio Klostermann, 1972, p. 356-375.

. Sein und Zeit. 16. ed. Tübingen: Max Niemeyer, 1986.

. Ser e tempo. Bragança Paulista: Edusf; Petrópolis: Vozes, 2006.

. Der Begriff der Zeit. 1. Der Begriff der Zeit (1924); 2. Der Begriff der Zeit (Vortrag 1924). Frankfurt am Main: Vittorio Klostermann, 2004.

. Der Begriff der Zeit. Tübingen: Max Niemeyer, 1989.

. "O conceito de tempo". In: Cadernos de Tradução, Departamento de Filosofia da USP, n. 2, 1997, p. 6-39.

. Die Grundprobleme der Phänomenologie. Frankfurt am Main: Vittorio Ǩlostermann, 1975.

. Os problemas fundamentais da fenomenologia. Petrópolis: Vozes, 2012.

. Die Frage nach dem Ding. Zu Kants Lehre von den transzendentalen Grundsätzen. Frankfurt am Main: Vittorio Klostermann, 1984.

. Que é uma coisa? Doutrina de Kant dos princípios transcendentais. Lisboa: Edições 70, 1992.

. Parmenides. Frankfurt am Main: Vittorio Klostermann, 1992.

. Parmênides. Bragança Paulista: Edusf; Petrópolis: Vozes, 2008.

25 Cf. BAMBACH, Charles R. Heidegger, Dilthey, and the crisis of historicism. Londres/Ithaca: Cornell University Press, 1995; também HEINZ, Marion. Zeitlichkeit und Temporalität im Frühwerk Martin Heideggers. Würzburg/Amsterdam: Königshausen \& Neumann/Rodopi, 1982, p. 138-163; DASTUR, Françoise. Heidegger e a questão do tempo. Lisboa: Instituto Piaget, 1997, p. 108-116.

26 Cf. HEIDEGGER, Martin. Der Begriff der Zeit. 1. Der Begriff der Zeit (1924); 2. Der Begriff der Zeit (Vortrag 1924), p. 5-15.

27 GADAMER, Hans-Georg. Verdade e método. Petrópolis: Vozes, 1998, p. 335s. Também FLASCH, Kurt. Was ist Zeit? Frankfurt am Main: Vittorio Klostermann, 1993, p. 37-42 e ANZOLA, Jaime Montero. "Reflexiones en torno a Ser y tiempo de Martin Heidegger". In: Franciscanum, Santafé de Bogotá, ano 37, n. 112, jan./abr. 1996, p. 36. 